$(-25.67 \%$ ) 和甲苯 $(-24.9 \% 0)$ 碳同位素值可比, 同 样反映了两类天然气及其相应源岩的差异.

\title{
5 结论
}

首次在奥陶系泥灰质沉积岩中发现类似于腐殖 型的烃源岩, 即类 通型烃源岩. 其特征是以宏观藻 为主要生烃母质, 具有类似于腐殖型母质的生烃结 构, 产物主要以天然气为主. 该类源岩和高等植物 出现后的腐殖型源岩具有许多相似的生物标志化合 物特征, 但奥陶纪时尚未出现构成腐殖质的木质素 和纤维素, 因此形成腐殖型干酪根时也不可能存在 复杂的腐殖化过程. 类 通型烃源岩生成的天然气在

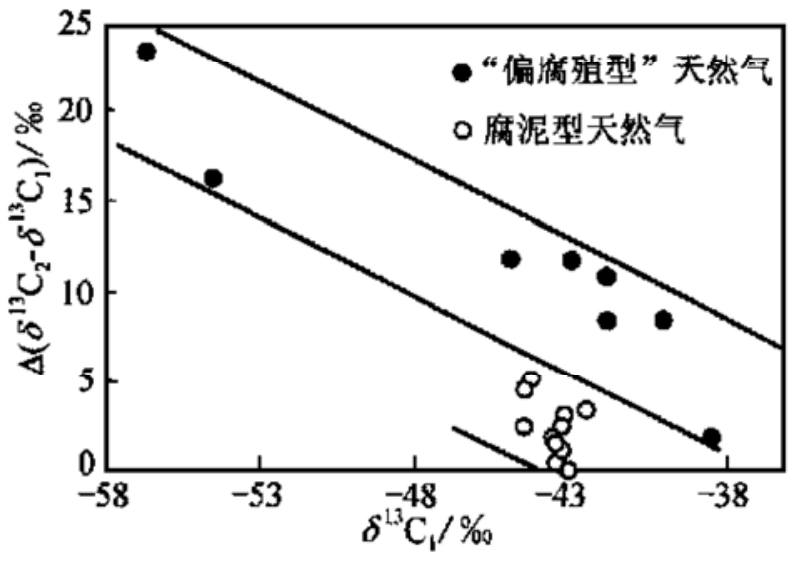
氮气含量和 $\delta^{13} \mathrm{C}_{2}$ 值上具有与腐泥型天然气明显的差异, 反映了相应源岩的特征.

致谢 感谢戴金星院士对本文作者的学术指导和对本文的修改、完善. 本工作为国家“九五”攻关专题“塔里木 盆地天然气分布规律及勘探方向”( 96 111-01-06) 资助项目.

\section{参 考 文 献}

1 Longmann M W, Palmer S E. Organic geochemistry of Mid continent Middle and Late Ordovician oils. American Association of Petrolum Geologist, 1987, 71: 938 950

2 Reed J D, Illich H A, Horsfield B. Biochemical evolutionary significance of Ordovician oils and their sources. Organic Geochemistry, 1986, 10: $347 \sim 358$

3 Hoffmann G F, Foster C B, Powell T G, et al. Hydrocarbon biomarkers from Ordovician sediments and the fossil alga Gloeocapsomorpha prisca Zalessky 1917. Geochimica et Cosmochimica Acta, 1987, 51: 2681 2687

4 Huang Difan, Zhao Mengjun. The geochemical Characteristics of marine oils in China. In: Progress in Geology of China ( 1993 1996) - Papers to 30th IGC, 1996, 800 804

5 赵孟军, 廖志勤, 黄第藩, 等. 从原油地化特征浅谈奥陶系原油生成的几个问题. 沉积学报, 1997, 15(4)：72 77

(1999-04 12 收稿)

\section{珠穆朗玛峰地区冰川净积累量变化的 冰芯记录及其气候意义}

\author{
侯书贵 秦大河 C.P. Wake ${ }^{(4)}$ P. A. Mayewski ${ }^{(4)}$ \\ 任贾文杨钦钊 ${ }^{(4)}$
}

( 中国科学院兰州冰川冻土研究所冰芯与寒区环境开放研究实验室, 兰州 730000; 4Climate Change Research Center, Institute for the Study of Earth, Oceans and Space (EOS), University of New Hampshire, Durham, NH 03824, USA)

摘要 根据珠穆朗玛峰地区远东线布冰川冰芯记录恢复了 50 年代中期以来冰川净积累量的变 化. 结果表明 60 年代冰川净积累量急剧减少, 70 90 年代初期的冰川年平均净积累量仅为 50 年 代后期相应值的一半左右. 珠峰地区冰川净积累量的减少与本区冰川自 50 年代以来的普遍退缩 现象一致, 其根本原因在于气温 (尤其是夏季气温) 升高所导致的冰川消融强度增大.

\section{关键词 珠峰地区 冰芯记录 冰川净积累量 气候}

根据冰芯记录恢复历史时期的冰川物质平衡, 是定量化研究冰川物质平衡变化和冰川对气 
候变化响应的有效途径, 同时也有助于预测未来气候变化条件下, 冰川物质平衡以及冰川水资源 等的可能变化趋势, 这对于观测时间序列较短的青藏高原而言意义尤甚 ${ }^{[1,2]}$. 本世纪60 70年代 曾对珠穆朗玛峰(下文简称珠峰) 地区现代冰川的物理特征进行过较系统地研究 ${ }^{[3,4]}$, 积累了一 定的研究资料. 1997 年 5 6月中国科学院兰州冰川冻土研究所与美国新罕布什尔大学气候变 化研究中心合作, 在珠峰地区远东线布冰川北支海拔 $6500 \mathrm{~m}$ 处钻取一支长 $40.94 \mathrm{~m}$ 冰芯. 本文 利用顶部 $10 \mathrm{~m}$ 冰芯的化学记录恢复了本区 50 年代中期以来的冰川净积累量变化. 并探讨其所 反映的气候意义.

\section{1 样品处理与分析}

样品处理采用美方业已建立的标准方式 ${ }^{[5,6]}$ 进行. 野外对冰芯物理剖面进行描述后, 以 $4 \mathrm{~cm}$ 等间距对冰芯顶部 $20 \mathrm{~m}$ 进行分割, 然后使用手术刀片将冰芯表层约 $2 \mathrm{~cm}$ 的圆环除去, 剩余 核心部分直接装入专用塑料样品瓶用于化学分析, 另收集刮下的冰质用于 $\beta$ 活化度分析(每个 $\beta$ 活化度样品质量约 $1 \sim 2 \mathrm{~kg}$, 大致对应 $50 \mathrm{~cm}$ 长度的冰芯). 其余冰芯在冻结状态下运回中国科学 院兰州冰川冻土研究所后, 在- $15^{\circ} \mathrm{C}$ 冷库内进行同样处理. 在中国科学院冰芯与寒区环境开放 研究实验室, 使用 MAT- 252 气体质谱仪完成样品的 $8^{18} \mathrm{O}$ 测量, 结果以“标准平均大洋水 (SMOW)” 的千分比表示, 精度在 $\pm 0.5 \%$ 之内. 在美国新罕布什尔大学气候变化研究中心使用 Dionex model 4000 离子色谱仪完成样品的主要阴、阳离子测量, 并同期完成 $\beta$ 活化度样品的分析工作.

\section{2 冰芯时间序列的建立}

冰芯研究的第一步是冰芯年代的建立. 围绕该问题, 使用了多种方法和技术手段以期获得 较精确的结果.

本世纪 50 年代以来, 全球性核试验使得大气层中的 $\beta$ 放射性物质含量急剧增加, 其在冰川 上沉积后, 可在冰芯内形成明显的 $\beta$ 活化度峰值. 由于全球性核试验的日期是已知的, 因此冰芯 内相应 $\beta$ 活化度峰值的日期也是一定的. 这提供了检验冰芯 50 年代以来的断代准确性的标尺.

Wushiki ${ }^{[7]}$ 根据珠峰南坡 Lhajung 气象台站所采集的一个年周期的降水样品资料, 发现本区季 风期前 (4 6月) 降水的 $\delta \mathrm{D}$ 高于其他季节降水的相应值, 而季风期 (7 9 月) 降水的 $\delta \mathrm{D}$ 最低, 并 将其归因于降水中稳定同位素的“降水量效应”. 降水中稳定同位素的这种季节变化特征也同样 存在于喜马拉雅山北坡地区 ${ }^{[8]}$. 在中低纬山地冰川上,春夏时形成污化面 ${ }^{[9]}$. 凡冰芯中污化面出 现层位, 就会伴随 $\mathrm{Ca}^{2+}, \mathrm{Mg}^{2+}$ 等陆源离子的浓度峰值. 夏季源自孟加拉湾和阿拉伯海的季风降 水 ${ }^{[10]}$ 也导致冰芯相应层位内 $\mathrm{Na}^{+}, \mathrm{Cl}^{-}$等海盐离子的浓度峰值 ${ }^{[1]}$. 因此在珠峰冰芯中, 稳定同位 素和主要离子浓度的年际变化有其内在的对应关系, 即高 $\delta^{18} \mathrm{O}$ 值大致对应各主要离子浓度的峰 值, 但一般存在位相差异, 这一点在年层判读时需注意 ${ }^{[9]}$.

以 $\beta$ 活化度峰值作为绝对年层, 以冰芯 $\delta^{18} O$ 剖面为主, 并以 $\mathrm{Ca}^{2+}, \mathrm{Na}^{+}$浓度剖面为辅所建立 的冰芯时间序列如图 1 所示. 需指出的是冰芯顶部若干年层仅对应 3 4 个冰芯样品, 由此可能 导致顶部冰芯断代的随机误差, 但并不影响经过平滑处理后的趋势分析结果.

\section{3 结果与讨论}

根据图 1 所建立的时间序列, 以及不同深度内的实测冰芯密度, 就可将年层厚度随深度的变 化转换为冰川净积累量随时间的变化 (图 2(a)). 为消除冰芯年层划分对冰川净积累量年际变化 的影响, 我们对冰川净积累量进行了 5 点滑动平均处理. 结果表明冰川净积累量自 60 年代中期 


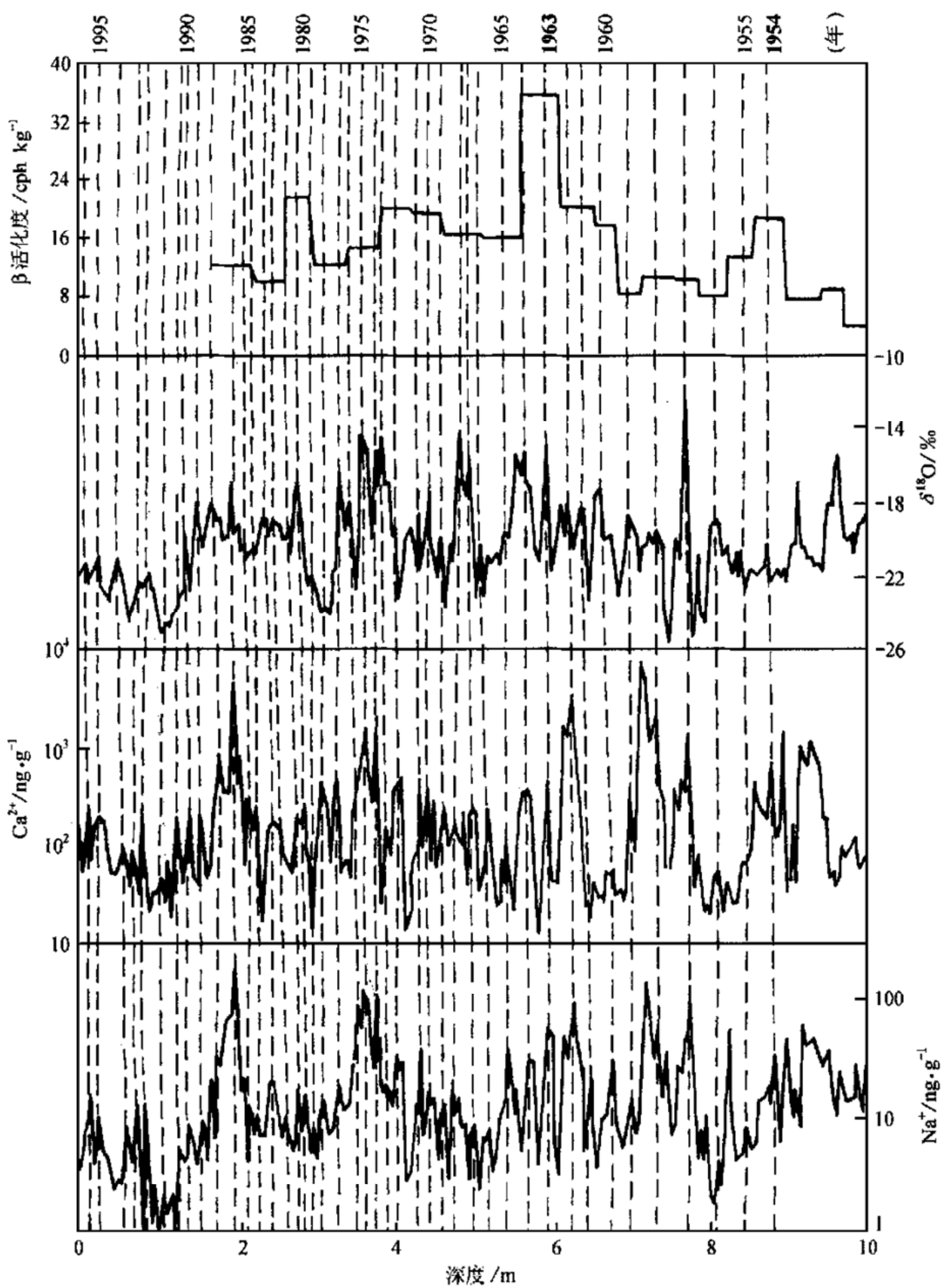

图 1 珠峰地区远东线布冰川冰芯的 $\beta$ 活化度、 $\delta^{18} \mathrm{O}$ 和主要离子浓度剖面以及冰芯时间序列结果 图中 $\beta$ 活化度峰值确定的标准年层分别为 1954 年和 1963 年

急剧降低, 70 90 年代初期的年平均净积累量仅及 50 年代后期相应值的一半左右. 实际上, 由 $\beta$ 活化度峰值所确定的 1954 1963 年和 1964 1996 年两时段内的年平均净积累量分别为 $27.1 \mathrm{~cm}$ 和 $15.1 \mathrm{~cm}$ 水当量, 同样表明了 60 年代中期以来冰川净积累量急剧减小这一事实.

研究表明夏季既是珠峰地区冰川的主要积累期, 同时也是主要的消融期 ${ }^{[4]}$, 因此珠峰地区冰 
川物质平衡状况应主要取决于本区夏季气温和 降水的变化. 为进一步探讨该问题, 图 2 也给出 了定日气象站自有记录以来的气温和降水变 化. 需要指出的是定日气象站自 1969 年起由定 日县定日区迁往协嘎尔区, 但两站址的纬度相 差无几( 前者为 $28^{\circ} 35^{\circ} \mathrm{N}$. 后者为 $28^{\circ} 38^{\prime} \mathrm{N}$ ). 且二 者海拔一致(均约为 $4300 \mathrm{~m}$ ), 因此搬迁对观测 资料连续性的影响不大(康兴成, 私人交流)。事 实上, 青藏高原上空自 60 年代后期开始 $500 \mathrm{hPa}$ 的地转风转为西偏南风, 这就加强了喜马拉雅 山北坡的焚风效应, 使该地区增温 ${ }^{[2]}$, 因此定日 气象站记录的 70 年代明显升温现象仍基本上 反映了本区的自然变化状况 (汤檚苍, 私人交 流). 考虑到定日气象站是距珠峰地区最近的气 象站,而且二者均位于喜马拉雅山北坡的雨影 区, 气候条件较相似, 因此我们趋向于认为定日 气象站比周围其他气象站更能反映珠峰地区的 气温和降水变化状况. 从图 2 可见本区 50 年代 后期的年平均气温虽然较高, 但夏季平均气温 较低, 且降水量较大, 从而导致 50 年代后期冰 川的高积累量. 在所研究时段内 60 年代初期的 气温最低, 虽然降水量也有所降低, 但由于冰川
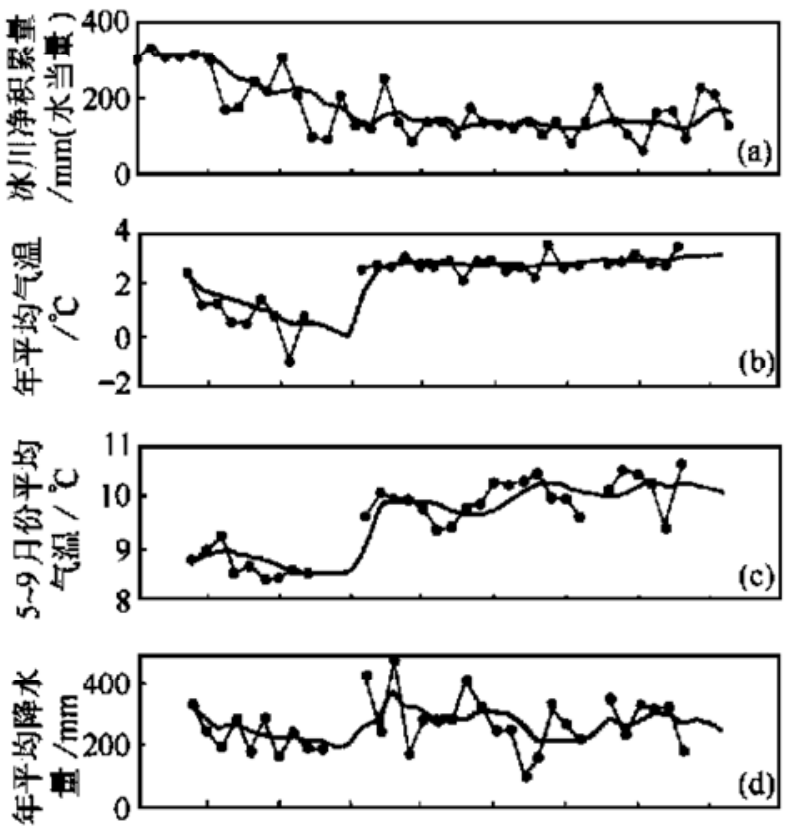

消融作用强度减弱, 该时段内的冰川净积累量也较高. 自 60 年代后期至 70 年代初年平均气温和 夏季平均气温均急剧上升, 并且 70 年代以后气温仍表现为波动式上升, 虽然这一时段内的降水 量有较显著的变化, 但冰川净积累量一直保持在较低水平. 根据本区的温湿特征与冰芯记录的 冰川净积累量变化, 可推断气温(尤其是夏季气温) 状况是决定本区冰川物质平衡的首要因素, 而 降水量的变化退居较次位置.

珠峰地区冰川物质平衡变化与本区冰川退缩现象一致. 郑本兴和施雅风 ${ }^{[3]}$ 通过比较 1959 年 和 1966 年所测的珠峰地区地图, 认为 1966 年东线布冰川冰塔区末端位置比 1959 年上移了约 $550 \mathrm{~m}$, 平均每年上移达 78 m. 1997 年珠峰考察期间我们采用 GPS 卫星测量技术对中线布冰川、 东线布冰川和远东线布冰川的末端及冰塔区末端进行了定位观测 ${ }^{1)}$. 结果表明远东线布冰川末 端在 1966 1997 年期间后退了约 $230 \mathrm{~m}$, 平均每年退缩量约为 $7.4 \mathrm{~m}$. 虽然 1997 年所测中线布冰 川和东线布冰川的末端位置与 1966 年所测位置基本重合, 但东线布冰川和中线布冰川冰塔区末 端在此期间分别后退了 $170 \mathrm{~m}$ 和 $270 \mathrm{~m}$, 年平均后退量分别为 $5.5 \mathrm{~m}$ 和 $8.7 \mathrm{~m}$. 中线布冰川和东线 布冰川末端位置的稳定性在于冰川末端区的表碛厚度很大, 如中线布冰川末端表碛厚度最高可 达 $6 \mathrm{~m}$ 左右 ${ }^{[3]}$, 有效地阻碍了下伏冰体的消融, 同时冰川末端与冰塔区断裂区间较长, 说明冰川

1) 井哲帆, 秦大河. 珠穆朗玛峰地区线布冰川末端变化观测及初步分析. 1998, 未发表 
末端区的冰体已成为死冰, 而冰川对气候变化的响应主要表现为冰塔区末端的位置变化.

自 60 年代以来的研究结果表明珠峰南坡孔布地区冰川也多处于退缩状态 ${ }^{[13,14]}$. Yamada 等 人 $^{[15]}$ 根据 1989 年对喜马拉雅山南坡孔布地区及其南侧的 Shorong 地区, 以及向西约 $100 \mathrm{~km}$ 外的 Langtang 地区的冰川末端位置的复测结果, 认为自 70 年代以来几乎所有的被测冰川均处于强烈 的退缩状态, 其中孔布地区的一支被测冰川末端位置自 1976 年 9 月至 1989 年 11 月退缩了约 $60 \mathrm{~m}$, 平均每年退缩量约为 $4.6 \mathrm{~m}$. 有研究表明孔布地区的冰川波动主要受控于气温的变化, 降

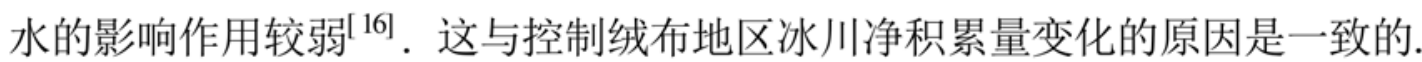

IPCC $^{[17]}$ 综合气候模式计算结果认为: 在按照不同方案限制温室气体排放的条件下, 全球气 温每 $10 \mathrm{a}$ 将增长 $0.1 \sim 0.2{ }^{\circ} \mathrm{C}$. 研究结果还表明青藏高原不仅与全球气候变暖具有同步性, 而且 还有超前于其他地区的可能性 ${ }^{[18,19]}$. 由于山地冰川对气候变暖最为敏感, 即使降水量增加 $20 \%$, 冰川所获得的补给量仍然小于气温上升 $1{ }^{\circ} \mathrm{C}$ 所加剧的冰川消融量. 可预测今后若干年内, 包括珠 峰地区在内的青藏高原山地冰川仍将以冰川持续退缩、厚度减薄、累积负平衡量增加的变化趋势 为主. 这不仅可能改变区域冰川水资源状况以及水循环过程, 从而对当地工农业用水产生不利 影响 ${ }^{[20]}$, 而且由于青藏高原在全球气候系统中的动力作用和热力作用, 青藏高原冰冻圈的任何 显著变化都可能对全球气候产生深远影响 ${ }^{[18,19,21]}$.

\section{4 结论}

珠峰地区远东线布冰川冰芯记录揭示了自 60 年代后期冰川净积累量急剧减少后, 至 90 年 代初期冰川一直保持在较低的物质平衡水平, 这与近几十年来珠峰南、北坡地区所观测的冰川波 动历史一致. 在全球气候变暖的背景下, 青藏高原冰川的上述变化趋势有可能进一步加剧, 这不 仅对区域发展产生不利影响, 而且可能对全球气候系统产生深远作用.

致谢＼cjkstart汤惁苍研究员和康兴成副研究员就气象资料的应用与作者进行了许多有益讨论,在此表示感谢. 本工作 为国家自然科学基金( 批准号: 49871022)、中国科学院“九五”重大项目 A( 批准号: KZ951-A1-402, KZ951-A1-204) 和 攀登计划 ( 批准号: 95-预-40) 资助项目.

\section{参 考 文 献}

1 姚檀栋, 焦克勤, 杨志红, 等. 古里雅冰芯中小冰期以来的气候变化. 中国科学, B 辑, 1995, 25( 10)：1108 1114

2 姚檀栋, 秦大河, 田立德, 等. 青藏高原 $2 \mathrm{ka}$ 来温度与降水变化一一古里雅冰芯记录. 中国科学, D 辑, 1996, 26(4)： 348 353

3 郑本兴, 施雅风. 珠穆朗玛峰地区冰川的变化. 见: 珠穆朗玛峰地区科学考察报告( 1966 1968) 一现代冰川与地貌. 北京: 科学出版社, 1975. 92 105

4 谢自楚. 线布冰川的消融特征. 见: 珠穆朗玛峰地区科学考察报告(1966 1968) 一一现代冰川与地貌. 北京: 科学出版 社, 1975. 65 70

5 Buck C F, Mayewski P A, Spencer M J, et al. Determination of major ions in snow and ice cores by ion chromatography. J Chromatogr, 1992, 594: 225 228

6 Whitlow S, Mayewski P A, Dibb J. A comparison of major chemical species seasonal concentration and accumulation at the South Pole and Summit, Greenland. Atmos Environ, 1992, 26A: 2045 2054

7 Wushiki H. Deuterium content in the Himalayan precipitation at Khumbu district, observed in 1974/ 75. Seppyo ( special issue), 1977, 39: $50 \sim 56$

8 Wake C P, Stievenard M. The amount effect and oxygen isotope ratios recorded in Himalayan snow. In: Proceedings of the IGBP PAGES/ PEP II Nagoya (Japan) Symposium, Nov 28 Dec 1, 1995. 
9 姚檀栋, 谢自楚, 武符舲, 等. 敦德冰帽中的小冰期气候记录. 中国科学, B 辑, 1990，11：1196 1201

10 林振耀, 吴祥定. 青藏高原水汽输送路径的探讨. 地理研究, 1990, 9(3)：802 809

11 Mayewski P A, Lyons W B, Ahmad N, et al. Interpretation of the chemical and physical time series retrieved from Sentik Glacier, Ladakh Himalayas, India. J Glciol, 1984, 30(104): 66 76

12 汤禁苍, 白重瑷, 刘晓东. 高原近代气候变化的事实分析. 见: 汤檚苍, 程国栋, 林振耀主编. 青藏高原近代气候变化及 其对环境的影响. 广州：广东科技出版社, 1998. 121 144

13 Higuchi K, Fushimi H, Ohata T, et al. Glacier inventory in the Dudh Kosi region, East Nepal. World Glacier Inventory, Proceedings of Reideralp Workshop Sep 1978, IAHS-AISH Publication No. 126, 1979, 92 100

14 Fushimi H, Ohata T. Fluctuation of glaciers from 1970 to 1978 in the Khumbu Himal, East Nepal. Seppyo, 1980, 41( special issue) : 1 5

15 Yamada T, Shiraiwa T, Iida, et al. Fluctuations of the glaciers from the 1970s to 1989 in the Khumbu, Shorong and Langtang regions, Nepal Himalayas. Bull Glacier Res, 1992, 10: 11 19

16 Seko K, Takahashi S. Characteristics of winter precipitation and its effect on glaciers in the Nepal Himalaya. Bull Glacier Res, 1991, 9: $9 \sim 16$

17 Houghton J T, Callander B A, Varney S K, eds. Intergovernmental Panel on Climate Change. Climate Change 1992, The IPCC Supplementary Report. Cambridge: Cambridge Univ Press, 1992. 200

18 冯 松, 汤禁苍, 王冬梅. 青藏高原是我国气候变化启动区的新证据. 科学通报, 1998, 43(6)：633 636

19 汤禁苍, 李存强. 关于青藏高原是气候变化启动区的分析事实. 见: 中国青藏高原研究会第一届学术讨论会论文选. 北 京: 科学出版社, 1992. 42 48

20 Lin Z Y, Chen X L. Climate change and its impact on crop yield in Tibet, China. J Agr Met, 1993, 48(5): 615 618

21 Barnett T P, Dumenil L, Schlese U, et al. The effect of Eurasian snow cover on global climate. Science, 239: 504 507

(1999-04-12 收稿)

\section{年轻火山岩的 $\mathbf{K}-\mathbf{A r}$ 年龄与过剩氩 二元混合模式及过剩氩影响的定量研究}

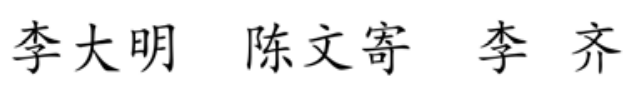

(中国地震局地质研究所, 北京 100029)

摘要 提出过剩氩的二元混合模式, 结合实验数据定量研究过剩氩对年轻火山岩真实 $\mathrm{K}-\mathrm{Ar}$ 年 龄的影响. 结果表明: 样品中含 $5 \%$ 过剩氩组分对 $2 \mathrm{Ma}$ 以上的 $\mathrm{K}-\mathrm{Ar}$ 年龄影响< $7.36 \%$, 对 0.5 $\mathrm{Ma}$ 的样品可使 $\mathrm{K}-\mathrm{Ar}$ 年龄升高约 $32.4 \%$; 而 $1 \%$ 的过剩氩组分则使 $0.5 \mathrm{Ma}$ 样品的 $\mathrm{K}-\mathrm{Ar}$ 年龄升 高 6. 26\%。因此, 经过预处理后过剩氩成分 $\leqslant 1 \%$ 时, 老于 $0.5 \mathrm{Ma}$ 样品的 $\mathrm{K}-\mathrm{Ar}$ 年龄应是可信 的. 利用基质测定年轻火山岩的 $\mathrm{K}-\mathrm{Ar}$ 年龄时, 对小于 $0.2 \mathrm{Ma}$ 的样品, 在过剩氩含量很高的情 况下, 即便基质中只含有 $1 \%$ 过剩氩组分也会对 $\mathrm{K}-\mathrm{Ar}$ 年龄产生很大影响.

\section{关键词 年轻火山岩 $\mathbf{K}-\mathbf{A r}$ 年龄 过剩氩 二元混合模式}

1948 年 Aldrich 和 Nier ${ }^{[1]}$ 首次发现并报道矿物中存在过剩氩, 而后其他学者又在一些海底 火山岩和大陆火山岩中发现过剩氩的存在( 比如南太平洋海底玄武岩中玻璃质, 夏威夷 $\mathrm{Ka}^{-}$ pubo 火山熔岩中橄榄石巨晶, 新西兰 Aukland 火山玄武岩玻璃质, 日本 Aira 火山灰中的火山玻 璃), 并认为过剩氩的存在会对 K-Ar 真实年龄产生影响. 1985 年, 陈文寄等人 ${ }^{[2]}$ 首次在大同第 四纪火山群的碱性玄武岩橄榄石斑晶中发现过剩氩, 其中 BB-6 火山岩的全岩年龄为 $(0.441 \pm$ 0. 013) $\mathrm{Ma}$, 而橄榄石斑晶年龄为(2.93 \pm 2.73$) \mathrm{Ma}$, 全岩样品去除橄榄石等弱磁性矿物后的基 